\title{
An alternative wind profile formulation for urban areas in neutral conditions
}

\author{
Armando Pelliccioni ${ }^{1}$, Paolo Monti ${ }^{2}$ and Giovanni Leuzzi ${ }^{2}$ \\ ${ }^{1}$ INAIL-DIPIA, Via Fontana Candida 1, 00040 Monteporzio Catone, Roma (Italy) \\ ${ }^{2}$ DICEA, Università di Roma "La Sapienza", Via Eudossiana 18, 00184 Roma (Italy)
}

Corresponding author:

Paolo Monti. Tel: 00390644585045. Fax:00390644585065; E-mail: paolo.monti@uniroma1.it

\begin{abstract}
On the basis of meteorological observations conducted within the city of Rome, Italy, a new formulation of the wind-speed profile valid in urban areas and neutral conditions is developed. It is found that the role played by the roughness length in the canonical log-law profile can be taken by a local length scale, depending on both the surface cover and the distance above the ground surface, which follows a pattern of exponential decrease with height. The results show that the proposed model leads to increased performance compared with that obtained by using other approaches found in the literature.
\end{abstract}

Key words: MOST; roughness length; wind profile; urban boundary layer, roughness sublayer; inertial sublayer. 


\section{Introduction}

Aerodynamic roughness (buildings and other structures), moisture availability and radiative and thermal properties (albedo, emissivity, heat capacity, thermal conductivity, among others) differentiate urban areas from their rural surroundings. This leads to the formation of a region defined as the urban boundary layer (UBL) [10, 22]. The analysis of the UBL, which is in general horizontally inhomogeneous and strongly dependent on the height, is complicated by the presence of internal boundary layers within internal boundary layers [12, 23], each of them with its own thermal and dynamical characteristics (as reviewed by Britter and Hanna [5]). A consequence is the need to develop alternative approaches to the classical similarity theory for flow modeling in urban complexes. To this end, the case of neutral atmosphere is the first step for any successive analysis in diabatic conditions.

One of the problems encountered in UBL studies is that the canonical Monin-Obukhov similarity theory (MOST), does not hold in that it is strictly valid for flat terrain only. For neutrally stratified UBLs, the mean horizontal velocity $\mathrm{u}$ as a function of the height $\mathrm{z}$ is usually described by the classical log-law [30]:

$$
\mathrm{u}(\mathrm{z})=\frac{\mathrm{u}_{*}}{\mathrm{k}} \ln \left[\frac{\mathrm{z}-\mathrm{d}_{0}}{\mathrm{z}_{0}}\right]
$$

where $\mathrm{z}_{0}$ is the roughness length, $\mathrm{d}_{0}$ the displacement height, $\mathrm{u}_{*}$ the friction velocity and $\mathrm{k}=0.4$ the von Karman constant. Equation (1) should be valid in the constant flux or inertial sublayer (ISL) overlying the roughness sublayer (RSL), i.e. the portion of atmosphere immediately above the urban canopy [5]. The RSL includes the height range in which the flow is strongly influenced by the roughness elements (buildings and vegetation) and the determination of its depth in terms of buildings height or other physical parameters is not a simple task $[8,29]$.

In flat terrain (i.e. $\mathrm{d}_{0}=0$ ) the roughness length can easily be estimated from well-known land-use categories [30] or in terms of the Reynolds number [11] and the Rossby number [31]. In urban canopies, $\mathrm{z}_{0}$ and $\mathrm{d}_{0}$ can be obtained by using morphometric methods (among others Macdonald et al. [20], hereinafter MGH98; Grimmond and Oke [13], hereinafter GO99; Di Sabatino et al. [9]). In the case of neutral atmosphere, Kastner-Klein and Rotach [17] (hereinafter KR04) estimated $\mathrm{z}_{0}$ and $\mathrm{d}_{0}$ using morphometric methods and calculated $\mathrm{u}_{*}$ from Eq. (1), while Cheng and Castro [6] (hereinafter CC02) calculated $z_{0}$ and $d_{0}$ starting from the measured shear stresses profile. More recently, Harman and Finnigan [14] developed profile functions, tested in vegetated canopies, which do not show discontinuity at the interface between RSL and ISL. In particular, they found a relationship for the 
vertical profile of the wind speed that is comprised of a canopy model coupled to a modified surfacelayer model, formulated through the mixed layer analogy for the flow at a canopy top. In essence, their model consists of an extension of the canonical log-law where the influence of the RSL is taken into account by introducing an additional function.

In an attempt to develop improved models for the wind-speed profile in urban areas for neutral conditions, we propose here a new formulation where the role played by the roughness length, i.e. the constant of integration of the vertical gradient of the wind-speed, is taken by a new "variable" quantity. Advanced analysis on the common meaning of $z_{0}$ and the procedure for its calculation can be found in the literature since the early 1970s. To our knowledge, Arya [3] was the first to consider that the roughness height could depend on stratification. More recently, Zilitinkevich et al. [32] showed that the atmospheric stability strongly affects $z_{0}$, especially for the stable case, where $z_{0}$ monotonically decreases as stability becomes stronger. Barlow et al. [4] found from observations taken in Salford, UK, a logarithmic layer up to $65 \mathrm{~m}$ height, while at higher elevations the velocity showed a different vertical gradient because of the presence of a change in surface cover upstream of the measurement station. Similarly, Li et al. [18] observed the presence of kinks at $100 \mathrm{~m}$ and $200 \mathrm{~m}$ levels in the vertical velocity profiles taken at Beijing, China. They argued that such abrupt variations could be attributed to the influence of the changes in surface roughness from suburban to urban terrain. From analysis of wind profiles taken at Uppsala, Sweden, Karlsson [16] found an apparent roughness length which was allowed to adjust to the different vertical layers (lower and upper layers) and atmospheric stability. Experimental analysis conducted in the same urban complex considered in the present study [25] reveals that, at least for neutral conditions, the optimal value of $z_{0}$ to be inserted in Eq. (1) decreases with height. At elevated layers, $\mathrm{z}_{0}$ tend to values close to those listed in typical urban land use categories.

Based on these last results, we conjectured that $\mathrm{z}_{0}$ may not be treated as a constant entity but as a variable parameter, the value of which might depend on both the flow characteristics and the height. An investigation is therefore presented here with the purpose to propose a relationship for the wind profile in the UBL - in neutral conditions - where the assumption of constant $\mathrm{z}_{0}$ is removed.

The analysis is conducted using a set of meteorological data taken from a site located within the city of Rome, Italy. Wind and temperature profiles taken from ground level $(\mathrm{z}=0)$ up to $200 \mathrm{~m}$ during one year by means of a RASS/SODAR system are used for the analysis together with data acquired close to the surface using a conventional meteorological station. The following section describes the field 
campaign. Section 3 reports the conceptual description of the proposed model, while Section 4 is devoted to the model evaluation. Conclusions are given in Section 5.

\section{Datasets}

The dataset refers to a field campaign conducted at the Villa Pamphili urban park (VP), a site located within the city of Rome, Italy, during the period June 2005-July 2006. That large feature (Fig. 1), situated in the west part of the city, $\left(41^{\circ} 53^{\prime} \mathrm{N}, 12^{\circ} 26^{\prime} \mathrm{E}\right)$, interrupts built-up zones. Local circulations with a pronounced diurnal cycle are usually predominant in that area for the most part of the year [2, 19, 21, 27]. The measurements were made away from buildings and trees (blue dot in Fig. 1) and hence the data can be considered as free from the immediate effects of obstacles.

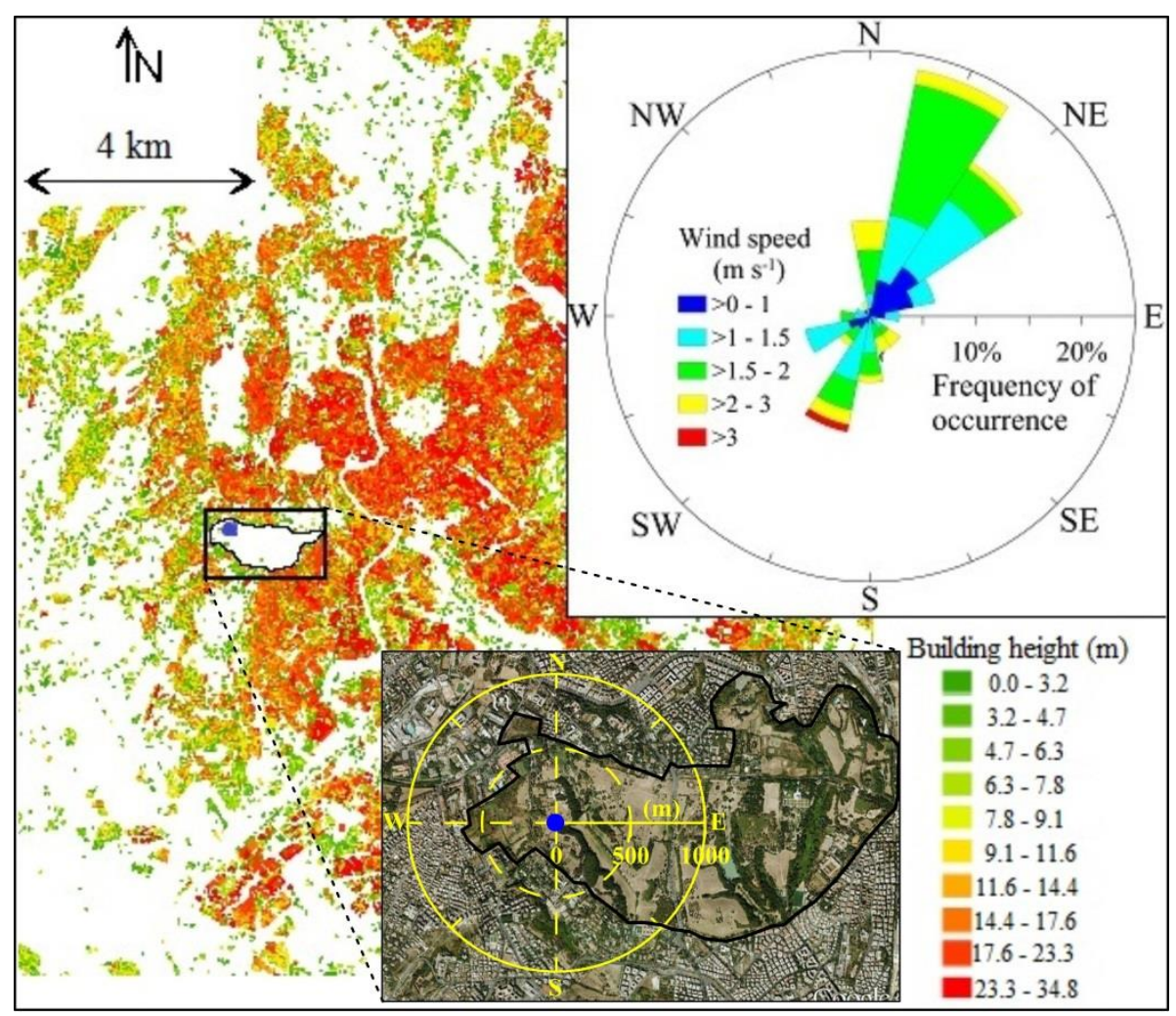

Fig. 1 Rome area. Colors are building heights. The black line within the rectangle indicates VP park, while the blue circle at the north-west part of VP refers to the location of the meteorological site. The inset (aerial picture produced using Google Earth) shows the enlargement of VP park. The wind rose calculated during neutral conditions using the ultrasonic anemometer at $\mathrm{z}=10 \mathrm{~m}$ is also shown

The meteorological instruments included a $10 \mathrm{~m}$ mast equipped with two triaxial ultrasonic anemometers (GILL Windmaster, sampling rate equal to $4 \mathrm{~Hz}$ ) mounted at $\mathrm{z}=5.5 \mathrm{~m}$ and $\mathrm{z}=10 \mathrm{~m}$ above 
the ground level. Two thermistors (Vaisala PT1000) placed at $\mathrm{z}=1.6 \mathrm{~m}$ and $\mathrm{z}=10 \mathrm{~m}$ provided measurements of the air temperature. Note that the acquisition frequency $(4 \mathrm{~Hz})$ of the ultrasonic anemometers is quite low compared to that generally used for measurements of turbulent variables $(\geq 10 \mathrm{~Hz})$. This might lead to underestimation of both statistical moments and eddy fluxes.

A SODAR/RASS system (Metek, model DSPA90) was used to measure the three components of the wind velocity and the virtual air temperature from $z=40 \mathrm{~m}$ up to $\mathrm{z}=400 \mathrm{~m}$ with a resolution of 20 $\mathrm{m}$. The system provided the vertical profiles of velocity and temperature averaged every $10 \mathrm{~min}$. Since the analysis regards the neutral boundary layer, a stringent criterion to select neutral conditions was adopted in order to minimize inaccuracies related to possible uncertainties in the estimation of the Obukhov length $\mathrm{L}=-\mathrm{u}_{*}^{3}\left(\mathrm{kq}_{0}\right)^{-1}$, used as an indicator of the flow stability $\left(\mathrm{q}_{0}\right.$ is the kinematic heat flux). In particular, only the vertical profiles corresponding to $|\mathrm{z} / \mathrm{L}| \leq 0.01$ were considered as representative of the statically neutral UBL. Here $\mathrm{z}=10 \mathrm{~m}$, i.e. the height of the top ultrasonic anemometer used to calculated $\mathrm{u}_{*}$. As both the ultrasonic anemometers and the thermometers used in the campaign did not give information on the temperature fluctuations, no directly measured heat flux $\mathrm{q}_{0}$ was available. This quantity may be estimated to reasonable precision based on the first order closure of the turbulence and temperature measured by the two thermistors (information on $\mathrm{q}_{0}$ estimation and further details on the field campaign can be found in Pelliccioni et al. [25]).

Given that during neutral conditions the distribution of the wind direction observed at VP was characterized by the N-NE direction (see wind rose in Fig. 1), in what follows only events of winds coming from that sector $\left(22.5^{\circ} \pm 11.25^{\circ}\right)$ are considered. Such a sector corresponds to a highly urbanized area, where the most representative building height $\mathrm{H}$ was nearly $18 \mathrm{~m}$. Finally, only the profiles that obey the condition of quasi-constancy of the wind direction along the vertical were retained. In particular, the vertical profile is discarded if the variation of wind direction in the range $10<\mathrm{z}<200 \mathrm{~m}$ is greater than $22.5^{\circ}$. In this way, 36 profiles were selected for the analysis. This is a concession to the requirement that the analysis is robust.

\section{The local length scale}

As a first step, we suppose that the length scale $\mathrm{z}_{0}$ which appears in the canonical log-law based on MOST, i.e. $u(z)=\left(u_{*} / k\right) \ln \left[z / z_{0}\right]$, is a quantity which depends not only on the surface characteristics but also on the height. As a consequence, we can introduce a new variable, $\mathrm{z}_{0 \mathrm{~L}}(\mathrm{z})$, which assumes the meaning of local length scale. Given wind speed observations in neutral conditions at several heights, one can define $\mathrm{z}_{\mathrm{OL}}$ simply by substitution of $\mathrm{z}_{0}$ by $\mathrm{z}_{\mathrm{OL}}$ : 


$$
\mathrm{u}(\mathrm{z})=\frac{\mathrm{u}_{*}}{\mathrm{k}} \ln \left[\frac{\mathrm{z}}{\mathrm{z}_{0 \mathrm{~L}}(\mathrm{z})}\right]
$$

Assuming $\mathrm{u}_{*}$ measured at a reference height, $\mathrm{z}_{\mathrm{ref}}$, Eq. (2) gives:

$$
\mathrm{z}_{0 \mathrm{~L}}(\mathrm{z})=\frac{\mathrm{z}}{\exp \left[\frac{\mathrm{u}(\mathrm{z}) \cdot \mathrm{k}}{\mathrm{u}_{*}\left(\mathrm{z}_{\mathrm{ref}}\right)}\right]}
$$

This procedure is generally used for calculating the (constant) values of $\mathrm{z}_{0}$ and $\mathrm{d}_{0}$ from Eq. (1) given the wind speed taken at two or more levels within the surface layer, where $\mathrm{u}_{*}$ does not vary with height [30]. Nevertheless, as will be shown below, the analysis of the wind profiles taken at VP suggests that $\mathrm{z}_{0 \mathrm{~L}}$ varies much with height even when $\mathrm{u}_{*}$ does not. Thus, we extend the use of the MOST even to the cases where it is not strictly valid.

\subsection{Experimental evidence}

Following the considerations above, we calculated $\mathrm{z}_{0 \mathrm{~L}}(\mathrm{z})$ for each vertical profile of the VP dataset using Eq. (3) and assuming $\mathrm{z}_{\mathrm{ref}}=10 \mathrm{~m}$ (the location of the ultrasonic anemometer). The average profiles of $\mathrm{z}_{0 \mathrm{~L}}(\mathrm{z})$ were grouped into 4 classes of $\mathrm{u}_{*}\left(\mathrm{z}_{\mathrm{ref}}\right)$, centred on the values $0.35,0.44,0.53$ and $0.64 \mathrm{~m} \mathrm{~s}^{-1}$ defined on the basis of the range of values calculated for $\mathrm{u}_{*}\left(\mathrm{z}_{\mathrm{ref}}\right)$ during the campaign. A fifth class referred to the value of the friction velocity averaged over all the 36 events, $\mathrm{u}_{*}\left(\mathrm{z}_{\mathrm{ref}}\right)=0.49 \mathrm{~m} \mathrm{~s}^{-1}$, was also used for the analysis.

Figure $2 \mathrm{a}$ shows the average profiles of $\mathrm{z}_{\mathrm{OL}}$ as a function of the non-dimensional height $\mathrm{z} / \mathrm{H}$. With the exclusion of the outlier data point obtained at $\mathrm{z}=10 \mathrm{~m}$ for $\mathrm{u}_{*}\left(\mathrm{z}_{\mathrm{ref}}\right)=0.35 \mathrm{~m} \mathrm{~s}^{-1}, \mathrm{z}_{0 \mathrm{~L}}$ is larger at low levels, nearly $3 \mathrm{~m}$, irrespective of $\mathrm{u}_{*}\left(\mathrm{z}_{\mathrm{ref}}\right)$. Moreover, the larger average $\mathrm{u}_{*}\left(\mathrm{z}_{\text {ref }}\right)$ the larger $\mathrm{z}_{0 \mathrm{~L}}$. As height increases $\mathrm{z}_{0 \mathrm{~L}}$ decreases until it reaches a minimum close to $0.5 \mathrm{~m}$ at $\mathrm{z} / \mathrm{H}=11.1$. Note that for $\mathrm{z} / \mathrm{H} \geq 6.6, \mathrm{z}_{\mathrm{OL}}$ is nearly constant and hence the classical log-law with constant roughness length holds. This suggests that an ISL should be present therein, while that is not true for $\mathrm{z} / \mathrm{H} \leq 6.6$.

As pointed out by Andreas et al. [1], the variability of $u_{*}$ with height is somewhat unimportant for the existence of the log-law in flat terrain for neutral conditions. This seems to be true also for the VP site. However, to verify whether the vertical variation of $\mathrm{z}_{0 \mathrm{~L}}$ could be ascribed to vertical variations of $\mathrm{u}_{*}$ or not, we calculated $\mathrm{u}_{*}(\mathrm{z})$ in an indirect way using the vertical profile of the measured standard 
deviation of the vertical velocity $\sigma_{\mathrm{w}}(\mathrm{z})$ (the SODAR system does not give information about the friction velocity). In particular, $\mathrm{u}_{*}(\mathrm{z})$ can be estimated, in the case of flat terrain and neutral conditions, from the relation $\mathrm{u}_{*}(\mathrm{z})=\mathrm{a} \cdot \sigma_{\mathrm{w}}(\mathrm{z})$, where a is a constant [24]. It follows that:

$$
\frac{\mathrm{u}_{*}(\mathrm{z})}{\mathrm{u}_{*}\left(\mathrm{z}_{\mathrm{ref}}\right)}=\frac{\sigma_{\mathrm{w}}(\mathrm{z})}{\sigma_{\mathrm{w}}\left(\mathrm{z}_{\mathrm{ref}}\right)}=\mathrm{R}(\mathrm{z})
$$

which gives the vertical profile of $\mathrm{u}_{*}(\mathrm{z})$ from $\mathrm{u}_{*}$ measured by the sonic anemometer at $\mathrm{z}_{\text {ref }}$ and from $\sigma_{\mathrm{w}}(\mathrm{z})$ acquired along $\mathrm{z}$ by the SODAR, viz.:

$$
\mathrm{u}_{*}(\mathrm{z})=\frac{\mathrm{u}_{*}\left(\mathrm{z}_{\mathrm{ref}}\right)}{\sigma_{\mathrm{w}}\left(\mathrm{z}_{\mathrm{ref}}\right)} \sigma_{\mathrm{w}}(\mathrm{z})=\mathrm{R}(\mathrm{z}) \cdot \sigma_{\mathrm{w}}(\mathrm{z})
$$
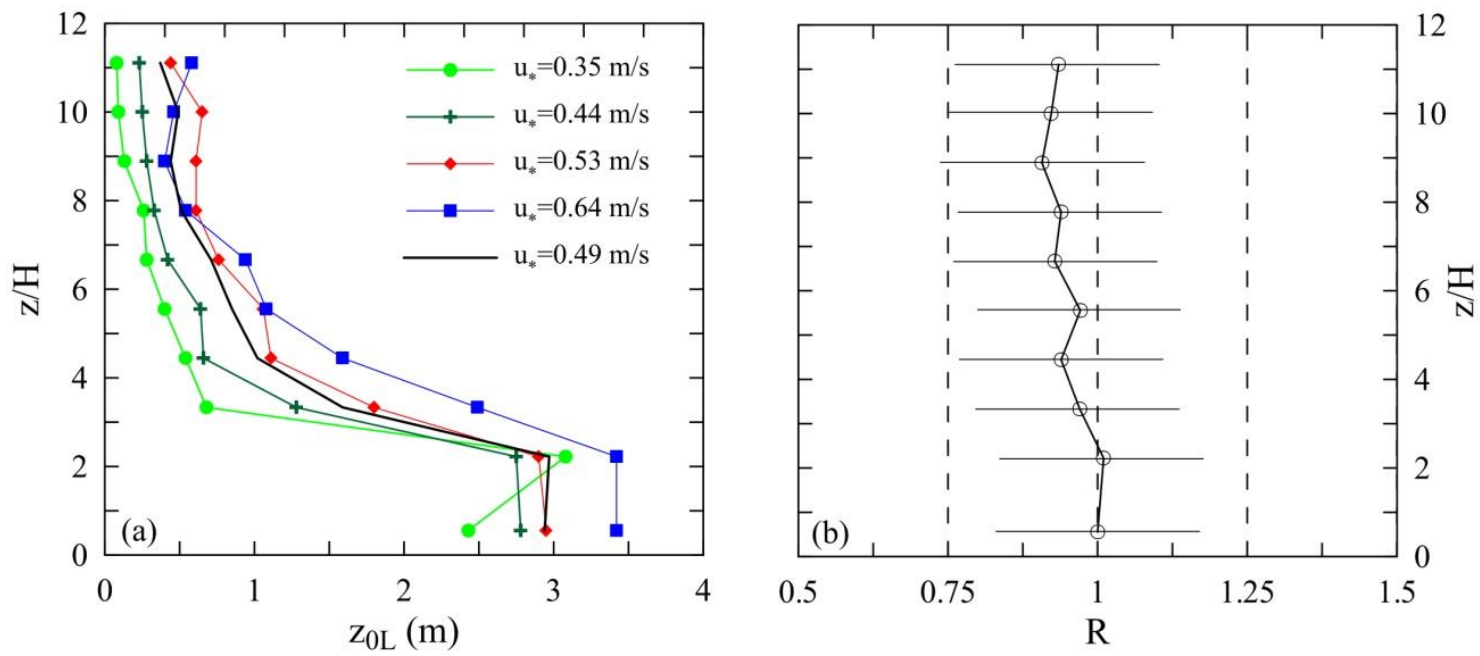

Fig. 2 (a) Vertical profiles of the averaged $z_{0 L}$ for classes of $u_{*}$. (b) Vertical profile of the ratio $\mathrm{R}(\mathrm{z} / \mathrm{H})=\mathrm{u}_{*}(\mathrm{z} / \mathrm{H}) / \mathrm{u}_{*}\left(\mathrm{z}_{\mathrm{ref}}=10 \mathrm{~m}\right)$. Note that the lower data point refers to the sonic anemometer. The error bar gives sample standard deviation

Figure $2 b$ shows $R$, calculated irrespective of the class of $u_{*}\left(z_{r e f}\right)$, as a function of $z / H$. It decreases slightly with $\mathrm{z} / \mathrm{H}$ and is about unity for $\mathrm{z} / \mathrm{H} \leq 5.5$. Thus, $\mathrm{u}_{*}$ decreases little with height too (its value at $\mathrm{z} / \mathrm{H}=11.1$ is nearly $90 \%$ the surface value) and hence a layer of quasi-constant mechanical flux above the surface seems to exist. Since the footprint analysis performed by [25] suggests that the flow at VP is strongly affected by the city, this means that a RSL is present and that $\mathrm{u}_{*}$ is nearly-constant therein. Therefore, the classical log-law with constant roughness length might be invalid in that portion of the UBL even if a quasi-constant flux layer is present. Similar results were obtained by Pelliccioni 
et al. [26] who analyzed vertical profiles of $\mathrm{u}_{*}$, taken in correspondence of an urban area, available in the CEDVAL dataset (compilation of wind tunnel datasets provided by the Environmental Wind Tunnel Laboratory of the Meteorological Institute of Hamburg University, see for example [15]). In particular, Pelliccioni et al. [26] found that under certain circumstances the classical log-law does not hold for $\mathrm{z} / \mathrm{H} \leq 3$ even though a quasi-constant flux layer exists, similarly to what was observed by Dallman et al. [7] in a suburban/industrial area. The accordance with what we observed at VP is less evident (the log-law is not valid at VP for $\mathrm{z} / \mathrm{H} \leq 6.6$ ). This discrepancy is perhaps reflective of the different characteristics of the land use upwind the measurement sites.

\subsection{Theoretical interpretation}

On the basis of the experiments reported in the previous sub-section, we may derive a suitable function $\mathrm{Z}_{0 \mathrm{~L}}(\mathrm{z})$, bearing in mind that it might depend also on the flow. In this context, the canonical roughness length should be considered as a zero-order approach, viz.:

$$
\frac{\mathrm{dz}}{\mathrm{dz}}=0
$$

from which results $\mathrm{z}_{0 \mathrm{~L}}=\mathrm{Z}_{0}=$ const. In a first-order approach, the right hand side of Eq. (6) is no longer zero, but is a function whose expression is not straightforward. With the constraint of a simple form for $\mathrm{Z}_{0 \mathrm{~L}}$, the first order approach with respect to Eq. (6):

$$
\frac{\mathrm{dz}}{\mathrm{dz}}=\beta^{\prime} \mathrm{z}_{0 \mathrm{~L}}+\gamma^{\prime}
$$

seems to be a reasonable choice. This closure leads to the zero-order Eq. (6) when $\beta^{\prime}=\gamma^{\prime}=0$. By integrating Eq. (7) one obtains:

$$
\int_{\mathrm{z}_{0 \mathrm{~S}}}^{\mathrm{z}_{\mathrm{L}}} \frac{\mathrm{dz} \mathrm{z}_{0 \mathrm{~L}}}{\beta \prime \mathrm{z}_{0 \mathrm{~L}}+\gamma^{\prime}}=\int_{0}^{\mathrm{z}} \mathrm{dz}
$$

where $\mathrm{z}_{0 \mathrm{~S}}=\left.\mathrm{z}_{0 \mathrm{~L}}\right|_{\mathrm{z}=0}$. Solving Eq. (8), one obtains:

$$
\mathrm{z}_{0 \mathrm{~L}}(\mathrm{z})=\left(\mathrm{z}_{0 \mathrm{~s}}+\frac{\gamma^{\prime}}{\beta^{\prime}}\right) \cdot \exp \left[\beta^{\prime} \cdot \mathrm{z}\right]-\frac{\gamma^{\prime}}{\beta^{\prime}}
$$


After making the change of variables $\alpha=\mathrm{z}_{0 \mathrm{~S}}+\gamma^{\prime} / \beta^{\prime}, \beta=-\beta^{\prime}$ and $\gamma=\gamma^{\prime} / \beta^{\prime}$, one obtains a functional form of $\mathrm{z}_{\mathrm{OL}}(\mathrm{z} ; \alpha, \beta, \gamma)$ totally equivalent to Eq. (9):

$$
\mathrm{z}_{0 \mathrm{~L}}(\mathrm{z})=\alpha \cdot \exp [-\beta \cdot \mathrm{z}]+\gamma
$$

The quantity $\beta$ can be viewed as the inverse of a length scale, $L_{C}=1 / \beta$, which has the role of incorporating the effects of the roughness elements on the undisturbed flow and, therefore, on the local length scale. Its value is connected to the complexity of the surface (from a geometrical point of view) and might be considered related to the RSL height. Introducing $\mathrm{L}_{\mathrm{C}}$ in Eq. (10) one gets the formulation of the vertical profile of $\mathrm{z}_{0 \mathrm{~L}}$ :

$$
\mathrm{z}_{0 \mathrm{~L}}(\mathrm{z})=\alpha \cdot \exp \left[-\frac{\mathrm{z}}{\mathrm{L}_{\mathrm{c}}}\right]+\gamma
$$

which shows that the local length scale consists of two parts: one takes into account the effects of the roughness elements (the larger $\mathrm{L}_{\mathrm{C}}$ the higher the complexity of the terrain) and a second one, corresponding to the asymptotic roughness length related to the city considered as a whole. In particular, from the analysis of Eq. (11), two asymptotic behaviors can be found for $\mathrm{z}_{\mathrm{OL}}(\mathrm{z})$ : at elevated levels

$$
\mathrm{z}_{0 \infty}=\lim _{\mathrm{z} \rightarrow \infty}\left(\mathrm{z}_{0 \mathrm{~L}}\right)=\lim _{\mathrm{z} \rightarrow \infty}\left(\alpha \cdot \exp \left[-\frac{\mathrm{z}}{\mathrm{L}_{\mathrm{c}}}\right]+\gamma\right)=\gamma
$$

and at the surface

$$
\mathrm{z}_{0 \mathrm{~S}}=\lim _{\mathrm{z} \rightarrow 0}\left(\mathrm{z}_{0 \mathrm{~L}}\right)=\lim _{\mathrm{z} \rightarrow 0}\left(\alpha \cdot \exp \left[-\frac{\mathrm{z}}{\mathrm{L}_{\mathrm{c}}}\right]+\gamma\right)=\alpha+\gamma
$$

It is worth noting that the role played by the local length scale can be viewed in terms of an additional contribution to the vertical gradient of wind speed with respect to the classic law where the roughness length is a constant. In fact, taking the derivative with respect to $\mathrm{z}$ of Eq. (1), one obtains $\mathrm{du} / \mathrm{dz}=$ $\partial \mathrm{u} / \partial \mathrm{z}=\mathrm{u}_{*} / \mathrm{kz}$. On the other hand, if $\mathrm{u}=\mathrm{u}\left(\mathrm{z}, \mathrm{z}_{0 \mathrm{~L}}\right)$ one has: 


$$
\frac{\mathrm{du}}{\mathrm{dz}}=\frac{\partial \mathrm{u}}{\partial \mathrm{z}}+\frac{\partial \mathrm{u}}{\partial \mathrm{z}_{0 \mathrm{~L}}} \frac{\mathrm{dz}}{\mathrm{dz}}
$$

where the first term at the right hand side of Eq. (14) is related to the classic form of $\mathrm{z}_{0}$. From Eqs. (2) and (10), the additional new term in (14) can be rewritten as:

$$
\frac{\partial \mathrm{u}}{\partial \mathrm{z}_{\mathrm{OL}}} \frac{\mathrm{dz}}{\mathrm{dz}}=\beta \frac{\mathrm{u}_{*}}{\mathrm{k}} \frac{\mathrm{z}_{\mathrm{OL}}-\gamma}{\mathrm{z}_{\mathrm{OL}}}
$$

which depends on $\mathrm{z}$, reaching a maximum at low levels and tending to zero at higher heights, where $\mathrm{z}_{0 \mathrm{~L}} \rightarrow \gamma$ (see Eq. 12). The importance of this term is weighted by the length scale $\mathrm{L}_{\mathrm{C}}=1 / \beta$, which modulates the magnitude of the deviation from the classical log-law. Note that Harman and Finnigan [14], who adopted Physick and Garratt's [28] idea to consider, in the framework of MOST, a function representing the effect of the canopy on the gradient of the wind profile above the canopy, introduced a correction to the similarity relationship for the wind-speed in vegetated canopies by adding a suitable function of height for the vertical flux of horizontal momentum. They have had the merit of introducing a natural form for the vertical profiles within the RSL that overcomes problems with many earlier forms in the literature. Unfortunately, their model does not seem to be easily extendable to urban canopies. The model we propose here solves in a radically different way the same problem by introducing the concept of local length scale.

Non-linear optimization algorithms applied to the vertical profile of $\mathrm{z}_{0 \mathrm{~L}}$ for $\mathrm{u}_{*}\left(\mathrm{z}_{\mathrm{ref}}\right)=0.49 \mathrm{~m} \mathrm{~s}^{-1}$ (Fig. 2a), in the height range $0.55<\mathrm{z} / \mathrm{H}<11.1$, gives $\alpha=3.247 \mathrm{~m}, \beta=0.016 \mathrm{~m}^{-1}$ and $\gamma=0.345 \mathrm{~m}$ (coefficient of variation $\mathrm{R}^{2}=0.89$ ). Since $\mathrm{L}_{\mathrm{C}}=\beta^{-1}=62.5 \mathrm{~m}$, it may be related to the height of the RSL. In fact, the ratio $\mathrm{L}_{C} / \mathrm{H} \cong 3$.5 belongs to the range of ratios between the RSL thickness and the building height found in the literature (see for example KR04). Furthermore, this ratio is not far from the lower limit of the range of constant $\mathrm{z}_{0 \mathrm{~L}}$ (see Fig. 2a). Regarding $\gamma$, its value is close to the values of the roughness length found in descriptive land-use types referred to urban complexes.

Note that Eq. (11) and related parameters should be considered valid only within the RSL and the portion of ISL below $\mathrm{z} / \mathrm{H}=11.1$. Preliminary tests suggest that $\alpha, \beta$ and $\gamma$ may be defined in terms of both the building height and the friction velocity. A detailed discussion on this subject will be reported elsewhere. 


\section{The velocity profiles}

To support the argument advanced in the previous section, we compare in Fig. 3a the wind velocity profiles obtained substituting Eq. (11) into the canonical log-law (hereinafter NM):

$$
\mathrm{u}(\mathrm{z})=\frac{\mathrm{u}_{*}}{\mathrm{k}} \ln \left[\frac{\mathrm{z}}{\alpha \cdot \exp \left[-\frac{\mathrm{z}}{\mathrm{L}_{\mathrm{c}}}\right]+\gamma}\right]
$$

with those calculated by applying other well-known models based on Eq. (1), which use morphometric methods such as those by MGH98 and KR04. Moreover, Eq. (1) is used also with $\mathrm{z}_{0}=0.033 \cdot \mathrm{H}$ and $\mathrm{d}_{0}=0.7 \cdot \mathrm{H}$ on the basis of the approach founded on the obstacle height (see GO99). Note that in all those three models $\mathrm{u}_{*}$ is not measured but calculated via best-fitting of the velocity profiles to the Eq. (1). An additional comparison is performed by using the method proposed by $\mathrm{CC} 02$, who calculated $\mathrm{z}_{0}$ and $\mathrm{d}_{0}$ via best-fitting to the Eq. (1) assuming for $\mathrm{u}_{*}$ values taken from the spatially averaged shear stresses measured in the ISL, the RSL or the whole surface layer. For ease of comparison between different models, only the cases in which $\mathrm{u}_{*}$ is averaged over the whole surface layer (CC02_SL) and that where $\mathrm{u}_{*}$ is measured at $\mathrm{z}_{\text {ref }}=10 \mathrm{~m}$ (CC02_zref) will be discussed here. Figure 3a depicts the wind profiles obtained by applying the aforementioned formulations. The velocities in the figure refer to the averages obtained over the same 36 profiles belonging to the interval $|\mathrm{z} / \mathrm{L}| \leq 0.01$ used to calculate $\alpha$, $\beta$ and $\gamma$.

The performance of the different models compared is assessed by the reproducibility parameter, RP (which represents the percentage deviation from the observed profile), viz.:

$$
\mathrm{RP}=\frac{1}{\mathrm{~N}_{\mathrm{p}}} \cdot \sum_{\mathrm{N}_{\mathrm{p}}} \sum_{\mathrm{z}_{\mathrm{k}}=10 \mathrm{~m}}^{\mathrm{z}_{\mathrm{k}}=200 \mathrm{~m}} \frac{\mathrm{u}\left(\mathrm{z}_{\mathrm{k}}\right)_{\mathrm{mod}}-\mathrm{u}\left(\mathrm{z}_{\mathrm{k}}\right)_{\mathrm{obs}} \mid}{\mathrm{u}\left(\mathrm{z}_{\mathrm{k}}\right)_{\mathrm{obs}}}
$$

where $\mathrm{N}_{\mathrm{P}}=36$ is the number of profiles. The coefficient of variation, $\mathrm{R}^{2}$, is also calculated by imposing the passage through the origin. NM and both the CC02 models show the best performance (Table 1). In particular, NM attains the maximum value of $\mathrm{R}^{2}(0.98)$, while both the CC02 models display a lower RP. Note that CC02_SL and CC02_zref show very similar performance as a result of the little variation of $u_{*}$ with height present in their experiment. Finally, it is also of interest that the values of $d_{0}$ calculated with both the CCO2 models are nearly twice as large as those expected since $\mathrm{d}_{0} \leq \mathrm{H}$. 



Fig. 3 (a) Vertical profiles of the observed (symbols) and modeled (colored lines) wind velocity for $|\mathrm{z} / \mathrm{L}|<0.01$. The profiles are averaged over the 36 events used to calculate the model parameters $\alpha, \beta$ and $\gamma$. (b) As in a), but using the 143 profiles belonging to the interval $0.01<|z / L|<0.02$ not used to calculate $\alpha, \beta$ and $\gamma$. Note that in a) the brown line associated with $\mathrm{CCO} 2$ zref is overlapped by the purple line.

\begin{tabular}{|c|c|c|c|c|c|c|}
\cline { 2 - 7 } \multicolumn{1}{c|}{} & NM & KR04 & MGH98 & GO99 & CC02_zref & CC02_SL \\
\hline $\mathbf{R P}$ & 5.6 & 29.3 & 10.3 & 28.9 & 5.6 & 5.5 \\
\hline $\mathbf{R}^{\mathbf{2}}$ & 0.98 & 0.74 & 0.34 & 0.78 & 0.92 & 0.91 \\
\hline $\mathbf{z}_{\mathbf{0}}(\mathbf{m})$ & - & 1.10 & 0.53 & 1.80 & 0.40 & 0.29 \\
\hline $\mathbf{d}_{\mathbf{0}}(\mathbf{m})$ & - & 16.9 & 15.1 & 12.6 & 30.9 & 32.6 \\
\hline
\end{tabular}

Table 1 Values of the reproducibility parameter (RP) and the coefficient of variation $\left(\mathrm{R}^{2}\right)$ of the wind velocity calculated for each model. $\alpha, \beta$ and $\gamma$ and the parameters are calculated for the same interval $|z / L|<0.01$. The values of $z_{0}$ and $d_{0}$ are also shown

To test further the model results, we use the same parameters $\alpha, \beta$ and $\gamma$ obtained for $|z / L|<0.01$ to calculate the 143 velocity profiles belonging to the interval of stability $0.01<|z / L|<0.02$, which can be considered representative of near-neutral conditions. Those profiles, not used to obtain $\alpha, \beta$ and $\gamma$, are nearly four times the number of profiles considered during the training phase. The results suggest that NM works reasonably well (see Fig. $3 b$ and Table 2), with performance higher than that shown by the other models. Among the classical approaches, the best results are obtained again by CC02_SL, even though the estimated $d_{0}$ seems to be too large. Note that all formulations give high correlation coefficients. In contrast, slopes and intercepts given by NM are clearly closer to the optimal values 
(respectively 1 and 0 ) compared to the other models. Therefore, NM simulates adequately not only the vertical trend of the wind velocity but also its absolute value.

\begin{tabular}{|c|c|c|c|c|c|c|}
\cline { 2 - 7 } \multicolumn{1}{c|}{} & NM & KR04 & MGH98 & GO99 & CC02_zref & CC02_SL \\
\hline RP & 7.5 & 14.3 & 9.3 & 20.9 & 6.1 & 9.4 \\
\hline $\mathbf{R}^{\mathbf{2}}$ & 0.97 & 0.93 & 0.93 & 0.94 & 0.92 & 0.92 \\
\hline Slope & 0.91 & 0.56 & 0.54 & 0.52 & 0.77 & 0.81 \\
\hline Intercept $\left(\mathbf{m ~ s}^{-\mathbf{1}}\right)$ & 0.14 & 1.64 & 2.56 & 1.38 & 1.33 & 1.37 \\
\hline
\end{tabular}

Table 2 Performance of the velocity profiles belonging to the interval $0.01<|z / L|<0.02$. The parameters $\alpha, \beta$ and $\gamma$ used to calculate the velocity profiles are the same as those calculated by considering the interval $|\mathrm{z} / \mathrm{L}|<0.01$

Finally, it is interesting to investigate the role played by the additional term in the velocity gradient relationship (Eq. 14). As is well-known, the MOST is based on the hypothesis that the nondimensional gradient of the wind-speed:

$$
\phi_{\mathrm{m}}=\frac{\mathrm{kz}}{\mathrm{u}_{*}} \frac{\mathrm{du}}{\mathrm{dz}}
$$

is unity. In contrast, for the classical log-law (Eq. 1):

$$
\phi_{\mathrm{m}}^{\mathrm{CL}}=\frac{z}{\mathrm{z}-\mathrm{d}_{0}}
$$

while for NM:

$$
\phi_{\mathrm{m}}^{\mathrm{NM}}=1+\beta \frac{\mathrm{z}_{\mathrm{z} 0}-\gamma}{\mathrm{z}_{0 \mathrm{z}}} \mathrm{z}
$$

Figure $4 \mathrm{a}$ depicts $\phi_{\mathrm{m}}^{\mathrm{CL}}$ and $\phi_{\mathrm{m}}^{\mathrm{NM}}$ calculated as a function of $\mathrm{z} / \mathrm{H}$ using the same dataset and all the above-mentioned formulations. Obviously, they all show a strong dependence on $\mathrm{z} / \mathrm{H}$. 

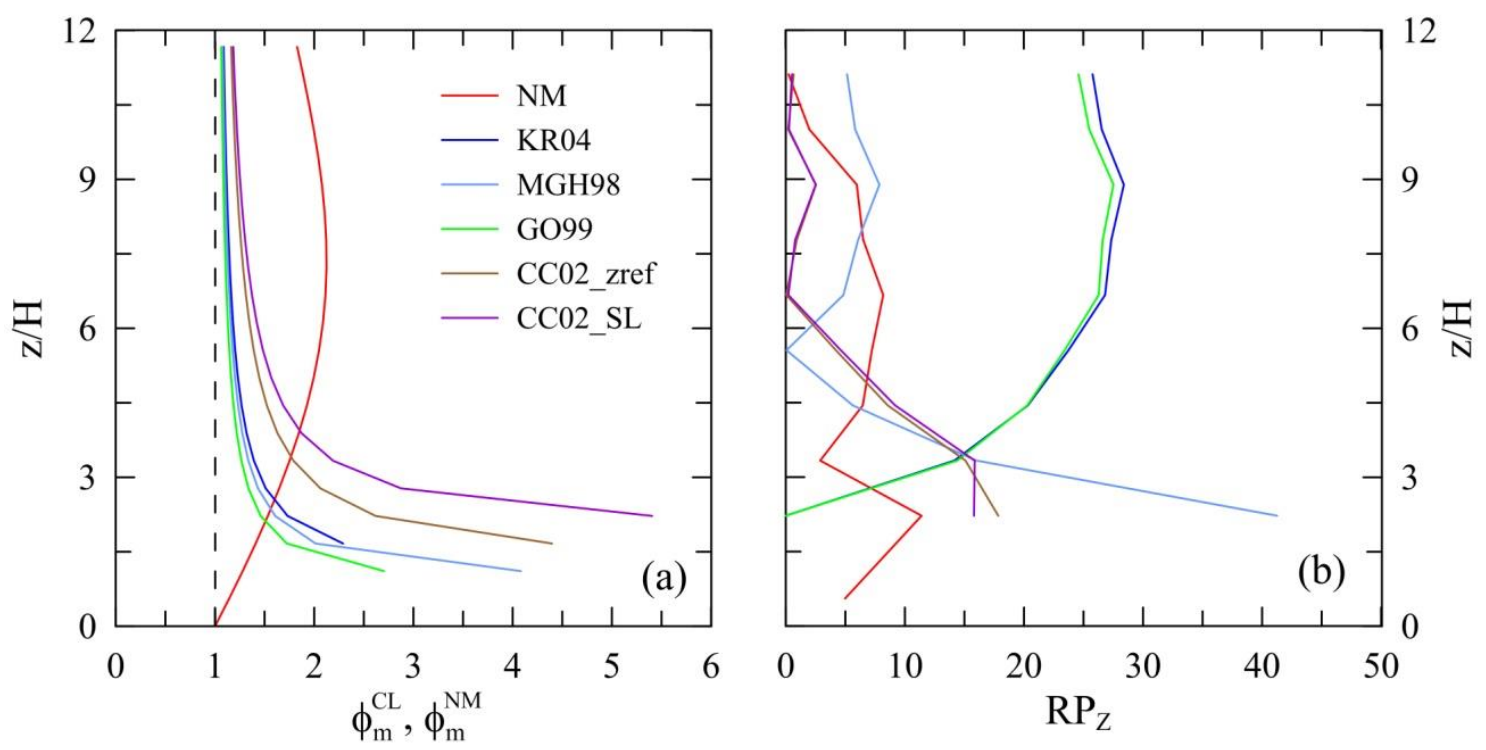

Fig. 4 (a) Non-dimensional velocity gradients $\phi_{\mathrm{m}}^{\mathrm{CL}}$ and $\phi_{\mathrm{m}}^{\mathrm{NM}}$ calculated for all the compared formulations as a function of the non-dimensional height. The dashed line indicates $\phi_{\mathrm{m}}=1$. (b) As in a) but for $\mathrm{RP}_{\mathrm{Z}}$. All data refer to $\mathrm{N}_{\mathrm{P}}=36$

While at elevated heights all the non-dimensional velocity gradients tend to unity, they differ substantially close to the surface in that $\phi_{\mathrm{m}}^{\mathrm{CL}} \rightarrow \infty$ for $\mathrm{z} \rightarrow \mathrm{d}_{0}$. In contrast, $\phi_{\mathrm{m}}^{\mathrm{NM}} \rightarrow 1$ at the surface (as for the MOST) and attains a maximum at $\mathrm{z} \cong 2 \cdot \mathrm{L}_{\mathrm{C}} \cong 130 \mathrm{~m}$. In other words, for $\mathrm{z} \rightarrow 0$ and $\mathrm{z} \rightarrow \infty$ NM shares the same behavior with the MOST (i.e. $\phi_{m}=1 \forall z$, dashed line in Fig. 4a), while for intermediate levels the additional term (Eq. 15) acts in modulating the wind velocity to take into account the RSL. This is reflected in the values of $\mathrm{RP}_{\mathrm{Z}}$, that is RP calculated as a function of the height (Fig. 4b). NM shows low $\mathrm{RP}_{\mathrm{Z}}$ irrespective of the height, while all formulations based on $\phi_{\mathrm{m}}^{\mathrm{CL}}$ exhibit much more variability of $\mathrm{RP}_{\mathrm{Z}}$; i.e. low $\mathrm{RP}_{\mathrm{Z}}$ at large $\mathrm{z} / \mathrm{H}$ are accompanied by high $\mathrm{RP}_{\mathrm{Z}}$ close to the surface and vice versa.

\section{Conclusions}

In this work we propose a new model to evaluate the wind profiles for neutral conditions in urban areas. We showed that the role played by the roughness length may be taken by a local length scale, $\mathrm{z}_{0 \mathrm{~L}}$, which depends on the altitude. A decrease of $\mathrm{z}_{0 \mathrm{~L}}$ with height up to $200 \mathrm{~m}$ above the ground was found, which cannot be explained in terms of the (little) vertical variation of $\mathrm{u}_{*}$ that takes place within the same height range. An interpretation of the experimental result is proposed, and a formulation of the local length scale which decays exponentially with height is introduced. The model is based on 
three parameters $\alpha, \mathrm{L}_{\mathrm{C}}$ and $\gamma$ to be estimated throughout experimental data. While $\mathrm{L}_{\mathrm{C}}$ and $\gamma$ appear to conform, respectively, to the RSL height and the classic roughness length derived from land-use types referred to urban complexes, the meaning of $\alpha$ is still not clear, except that it might be linked with the local roughness elements. The overall performance of the modeled vertical profiles of the wind velocity is better than that shown by other models that have been proposed in the literature. This is valid also considering vertical velocity profiles referred to near-neutral conditions $(0.01<|\mathrm{z} / \mathrm{L}|<0.02)$ adopting the same model parameters calculated for $|z / L|<0.01$. Finally, the proposed model might pave the way for new formulations of the wind profile also for diabatic conditions.

\section{ACKNOWLEDGEMENTS}

We are grateful to Dr. C. Gariazzo for his collaboration during the field campaign. 


\section{REFERENCES}

[1] Andreas EL, Claffey KJ, Jordan RE, Fairall CW, Guest PS, Persson POG, Grachev AA (2006) Evaluations of the von Karman constant in the atmospheric surface layer. J Fluid Mech 559:117149.

[2] Argentini S, Pietroni I, Gariazzo C, Amicarelli A, Mastrantonio G, Pelliccioni A, Petenko I, Viola A (2009) Boundary layer temperature profiles by a RASS and a microwave radiometer: Differences, limits and advantages. Nuovo Cimento B 124: 549-564.

[3] Arya SPS (1975) Buoyancy effects in a horizontal flat-plane boundary layer. J Fluid Mech 68:321343.

[4] Barlow JF, Rooney GG, von Hünerbein S, Bradley SG (2008) Relating urban surface-layer structure to upwind terrain for the Salford Experiment (Salfex). Bound-Lay Meteorol 127:173-191.

[5] Britter RE, Hanna SR (2003) Flow and dispersion in urban areas. Annu Rev Fluid Mech 35:469496.

[6] Cheng H, Castro IP (2002) Near wall flow over urban-like roughness. Bound-Lay Meteorol 104:229-259.

[7] Dallman A, Di Sabatino S, Fernando HJS (2013) Flow and turbulence in an industrial/suburban roughness canopy. Environ Fluid Mech 13:279-307.

[8] De Ridder K (2010) Bulk transfer relations for the Roughness sublayer. Bound-Lay Meteorol 134:257-267.

[9] Di Sabatino S, Leo LS, Cataldo R, Ratti C, Britter RE (2010) Construction of digital elevation models for a southern European city and a comparative morphological analysis with respect to northern European and north American cities. J Appl Meteorol Climatol 49:1377-1396.

[10] Fernando HJS (2010) Fluid dynamics of urban atmospheres in complex terrain. Annu Rev Fluid Mech 42:365-389.

[11] Frenzen P, Vogel CA (1995) On the magnitude and apparent range of variation if the von Karman constant in the atmospheric surface layer. Bound-Lay Meteor 72:371-392.

[12] Garrat JR (1992) The atmospheric boundary layer. Cambridge University Press, Cambridge.

[13] Grimmond CSB, Oke TR (1999) Aerodynamic properties of urban areas derived from analysis of urban surface form. J Appl Meteorol 38:1261-1292.

[14] Harman IN, Finnigan JJ (2007) A simple unified theory for flow in the canopy and roughness sublayer. Bound-Lay Meteorol 123:339-363.

[15] Hertwig D, Efthimiou GC, Bartzis JC, Leitl B (2012) CFD-RANS model validation of turbulent flow in a semi-idealized urban canopy. J Wind Eng Ind Aerodyn 111:61-72.

[16] Karlsson S (1986) The applicability of wind profile formulas to an urban-rural interface site. Bound-Lay Meteorol 34:333-355.

[17] Kastner-Klein P, Rotach MW (2004) Mean flow and turbulence characteristics in an urban roughness sublayer. Bound-Lay Meteor 111:55-84.

[18] Li QS, Zhi LH, Hu F (2009) Field monitoring of boundary layer wind characteristics in urban area. Wind Struct 12:553-574.

[19] Leuzzi G, Monti P (1997) Breeze Analysis by Mast and Sodar Measurements. Nuovo Cimento C 20:343-359.

[20] Macdonald RW, Griffiths RS, Hall DJ (1998) An Improved Method for the Estimation of Surface Roughness of Obstacle Arrays. Atmos Environ 32:1857-1894.

[21] Monti P, Leuzzi G (2005) A numerical study of mesoscale flow and dispersion over coastal complex terrain. Int J Environ Pollut 25 Nos 1/2/3/4:239-250.

[22] Oke TR (1976) The distinction between canopy and boundary-layer urban heat island. Atmosphere $14: 268-277$.

[23] Oke TR (1988) Boundary layer climates. Routledge, New York. 
[24] Panofsky HA, Dutton JA (1984) Atmospheric Turbulence. John Wiley \& Sons, New York.

[25] Pelliccioni A, Monti P, Gariazzo C, Leuzzi G (2012) Some characteristics of the urban boundary layer above Rome, Italy, and applicability of Monin-Obukhov similarity. Environ Fluid Mech 12:405-428.

[26] Pelliccioni A, Monti P, Leuzzi G (2014) Roughness length parameterization in urban boundary layers. Int J Environ Pollut, In press.

[27] Petenko I, Mastrantonio G, Viola A, Argentini S, Coniglio L, Monti P, Leuzzi G (2011) Local circulation diurnal patterns and their relationship with large-scale flows in a coastal area of the Tyrrhenian Sea. Bound-Lay Meteorol 139:353-366.

[28] Physick WL, Garratt JR (1995) Incorporation of a high-roughness lower boundary into a mesoscale model for studies of dry deposition over a complex terrain. Bound-Lay Meteorol 74:5571.

[29] Pournazeri S, Venkatram A, Princevac M, Tan S, Schulte N (2012) Estimating the height of the nocturnal boundary layer for dispersion applications. Atmos Environ 54:611-623.

[30] Stull RB (1988) An introduction to Boundary Layer Meteorology. Kluwer Academic Publisher, Dordrecht.

[31] Tennekes H (1973) The logarithmic wind profile. J Atmos Sci 30:234-238.

[32] Zilitinkevich SS, Mammarella I, Baklanov AA, Joffre SM (2008) The effect of stratification on the aerodynamic roughness length and displacement height. Bound-Lay Meteorol 129:179-190. 